\title{
Comparing Neonatal Outcome Following the Use of Ondansetron versus Vitamin B6 in Pregnant Females with Morning Sickness: A Randomized Clinical Trial
}

\author{
Zahra Shahraki, ${ }^{1}$ Zohre Sadat Hashemi Bonjar, ${ }^{1}$ Forough Forghani, ${ }^{1,}$ and Rezvane Nakhai ${ }^{1}$ \\ ${ }^{1}$ Obstetrics and Gynecology Department, Zabol University of Medical Sciences, Zabol, IR Iran \\ "Corresponding author: Forough Forghani, Obstetrics and Gynecology Department, Zabol University of Medical Sciences, P. O. Box: 9861979917, Zabol, IR Iran. Tel/Fax: \\ +98-543-2295117, E-mail: Forough_iran2005@yahoo.com
}

Received 2016 March 28; Revised 2016 July 06; Accepted 2016 August 28.

\begin{abstract}
Background: Pregnancy-related nausea and vomiting or morning sickness with an overall prevalence rate of $80 \%$ is commonly appeared at the eighth week and frequently disappeared in most pregnant females at the 16th week of gestation. The severe form of the condition named hyperemesis occurs in one per 200 to 300 pregnancies; it is accompanied by dehydration, electrolyte instability and nutritional deficits and needs medical interventions. Limited data are available on harmful effects of common antiemetic medications used within pregnancy on human neonates.

Objectives: The current study aimed to compare the effects of ondansetron and vitamin B6 on neonatal outcome in pregnant females with pregnancy-related nausea and vomiting. Neonatal outcome included the probable difference in neonates' gestational age, weight, height, head circumference and frequency of apparent congenital anomalies.

Methods: This randomized double-blinded clinical trial was conducted on 188 primipara singleton pregnant females with pregnancy-related nausea and vomiting who referred to state healthcare centers of Zabol, Iran, in 2014. The pregnant females were randomly assigned to receive drug packages including ondansetron tablets ( $4 \mathrm{mg}$ ) or vitamin B6 tablets ( $40 \mathrm{mg}$ ) and patients were instructed to take one tablet twice daily. Females were followed up until delivery and neonatal outcomes including any congenital anomaly, weight, height and head circumference at birth were assessed.

Results: There was no difference between the groups in the mean age of mother and the mean age of gestation. No differences were found between the groups regarding birth weight (3006.93 \pm 441.86 versus $2949.65 \pm 457.36 \mathrm{~g}, \mathrm{P}=0.67$ ), height at birth ( $49.50 \pm 1.45$ versus $48.97 \pm 1.47 \mathrm{~cm}, \mathrm{P}=0.75)$ and head circumference at birth $(34.23 \pm 1.22$ versus $33.88 \pm 1.26 \mathrm{~cm}, \mathrm{P}=0.56)$. No neonatal anomaly was observed in the two groups.
\end{abstract}

Conclusions: No significant differences were observed between the groups based on the neonatal outcome including neonatal anthropometric parameters and lack of congenital anomaly.

Keywords: Ondansetron, Pregnancy, Vitamin B6, Morning Sickness, Hyperemesis Gravidarum

\section{Background}

Pregnancy-related nausea and vomiting or morning sickness with an overall prevalence of $80 \%$ is commonly appeared at the eighth week and frequently disappeared in most pregnant females at the 16th week of gestation (1). The severe form of condition named hyperemesis occurs in one per 200 to 300 pregnancies; it is accompanied by dehydration, electrolyte instability and nutritional deficits and need medical interventions (2). These interventions vary from antiemetic drug use to nasogastric feeding and hyper-alimentation (3). In some cases, reversible liver dysfunction is also common and in this regard, hospitalization is indicated in about $0.5 \%$ to $0.8 \%$. It is revealed that severe morning thickness is associated with increased level of pregnancy-related hormones including human chorionic gonadotropin, estrogen, proges- terone, placental growth hormone, prolactin, thyroid hormones and adrenocorticotropin (4). Psychosocial factors such as unintended pregnancy as well as obesity and nulliparity are other triggering factors affecting morning sickness $(5,6)$. Ondansetron is a serotonin 5-HT3 receptor antagonist used to prevent nausea and vomiting caused by cancer chemotherapy, radiation therapy, and surgery and thus is considered in the list of medications needed in a basic health system (7). Ondansetron is a highly specific and selective serotonin 5-HT3 receptor antagonist with low affinity for dopamine receptors. The 5-HT3 receptors are present both peripherally on vagal nerve terminals and centrally in the chemoreceptor trigger zone of the area postrema. Ondansetron is used off-table to treat morning sickness and hyperemesis gravidarum of pregnancy.

Animal reproduction studies did not show evidence of

Copyright (c) 2016, Iranian Society of Pediatrics. This is an open-access article distributed under the terms of the Creative Commons Attribution-NonCommercial 4.0 International License (http://creativecommons.org/licenses/by-nc/4.0/) which permits copy and redistribute the material just in noncommercial usages, provided the original work is properly cited. 
harm to the baby or impairment of fertility by high daily doses of ondansetron; however limited data are available in its harmful effects on human neonates. A study of over 600,000 pregnancies in Denmark found that ondansetron during pregnancy was not associated with a significantly increased risk of spontaneous abortion, stillbirth, major birth defect, preterm birth, low birth weight, or small-forgestational-age (8). Another study concluded a 30\% increase in major congenital malformations due to an increase in heart problems among the babies (9).

Another safe medication used for morning sickness is a combination of vitamin B6 and doxylamine that still remains the only medication specially labeled for the treatment of nausea and vomiting of pregnancy (NVP) by the United States food and drug administration (FDA). Multiple studies showed no increased risk of birth defects (10). Some small studies demonstrated that vitamin B6 in its standard dosage (30 to $75 \mathrm{mg}$ per day) was more effective than placebo to control nausea and vomiting in pregnant females (11), however more studies on human models should be performed to approve its efficacy and lack of fetal harmful effects.

\section{Objectives}

The current study aimed to compare the effects of ondansetron (Demitron, Tehran Chemie Pharmaceutical Co., Tehran, Iran) and vitamin B6 (pyridoxine hydrochloride, Iran Hormone Pharmaceutical Co., Tehran, Iran) on neonatal outcome in pregnant females with pregnancy-related nausea and vomiting.

\section{Methods}

This randomized double-blinded clinical trial included 200 primipara singleton pregnant females with pregnancy-related nausea and vomiting who were referred from the state healthcare centers to Amir-Almomenin hospital from June 2014 to March 2015. The study aimed to detect the differences between the two groups in neonatal outcomes. Neonatal outcomes included the probable differences in neonates' gestational age, weight, height, head circumference and frequency of apparent congenital anomalies. The exclusion criteria were multi-gestational status, patients' refusal of antiemetic medication, history of drug allergy, other underlying disorders such as migraine headache, acute gastroenteritis, acute appendicitis, hepatitis, hydatidiform mole, or urinary tract infections, history of using other types of antiemetic drugs in recent weeks, addiction or reproductive assisted technologies. The sample size was calculated based on a previous study in which Ghahiri et al. (12) investigated the reducing impact of the ondansetron on number of pregnant females vomiting. Considering $\mathrm{P} 1=0.20$ and $\mathrm{P} 2=0.35$ and according to $95 \%$ confidence interval and test power of $80 \%$, it was estimated that 75 subjects were needed in each group. However, 100 pregnant females were recruited in each group to achieve more reliable results. The study protocol was approved by the research ethics committee of the study hospital. In this trial, four healthcare centers in Zabol were randomly selected from the state healthcare centers in the region. In each center, pregnant females with morning sickness were informed about the research and its objectives; 188 pregnant females with morning sickness signed consent forms; then they were randomly assigned to receive drug packages with "A" or "B" letter. Package "A" contained ondansetron tablets $(4 \mathrm{mg})$ and package "B" vitamin $\mathrm{B} 6$ tablets $(40 \mathrm{mg})$ and patients were instructed to take one tablet twice daily. Ondansetron and vitamin B6 were initiated on an average of 4 to 16 weeks gestation. All baseline characteristics were collected from the recorded files. Pregnant females were routinely followed up until delivery and neonatal outcomes including any congenital anomaly, weight, height and head circumference at birth were finally assessed and compared between the two groups.

Results were presented as mean \pm standard deviation (SD) for quantitative variables and by absolute frequencies and percentages for categorical variables. Categorical variables were compared using Chi-square test or Fisher exact test when more than $20 \%$ of cells with expected count of less than five were observed. Quantitative variables were also compared with T-test or non-parametric MannWhitney U test. Statistical significance was determined as a P Value $\leq 0.05$. All statistical analyses were performed by SPSS software (IBM SPSS Statistics for Windows, Version 19.0. Armonk, NY: IBM Corp).

\section{Results}

Among the females classified to receive ondansetron, only 88 continued their medication, but all subjects in vitamin B6 group completed the study protocol. Type of delivery was normal vaginal delivery except 27 in vitamin B6 and 28 in ondansetron group who underwent cesarean section. Four and five newborns who needed intensive care admitted to the intensive care unit (ICU) in vitamin B6 and ondansetron groups, respectively. There was no difference between the females in ondansetron and vitamin B6 groups in the mean age $(24.77 \pm 3.29$ years versus $24.89 \pm$ 3.97 years, $\mathrm{P}=0.84)$ and mean gestational age $(38.49 \pm 1.20$ weeks versus $38.60 \pm 1.48$ weeks, $\mathrm{P}=0.94)$. No differences 
Table 1. Comparing Maternal Characteristics and Neonatal Outcomes in the Study Groups

\begin{tabular}{lccc}
\hline Item & $\begin{array}{c}\text { Ondansetron } \\
\text { Group }, \mathbf{n}=\mathbf{8 8}\end{array}$ & $\begin{array}{c}\text { Vitamin B6 } \\
\text { Group, } \mathbf{n}=\mathbf{1 0 0}\end{array}$ & $\begin{array}{c}\text { P } \\
\text { Value }\end{array}$ \\
\hline Mother age, $\mathbf{y}$ & $24.77 \pm 3.29$ & $24.89 \pm 3.97$ & 0.84 \\
\hline Gestational age, $\mathbf{w}$ & $38.49 \pm 1.20$ & $38.60 \pm 1.48$ & 0.94 \\
\hline Birth-weight, $\mathbf{g}$ & $3006.93 \pm 441.86$ & $2949.65 \pm 457.36$ & 0.67 \\
\hline Height at birth, $\mathbf{c m}$ & $49.50 \pm 1.45$ & $48.97 \pm 1.47$ & 0.75 \\
\hline $\begin{array}{l}\text { Head circumference } \\
\text { at birth, cm }\end{array}$ & $34.23 \pm 1.22$ & $33.88 \pm 1.26$ & 0.56 \\
\hline
\end{tabular}

were found between the neonates in ondansetron and vitamin B6 groups regarding birth-weight (3006.93 $\pm 441.86 \mathrm{~g}$ versus 2949.65 $\pm 457.36 \mathrm{~g}, \mathrm{P}=0.67$ ), height at birth (49.50 \pm $1.45 \mathrm{~cm}$ versus $48.97 \pm 1.47 \mathrm{~cm}, \mathrm{P}=0.75)$ and head circumference at birth $(34.23 \pm 1.22 \mathrm{~cm}$ versus $33.88 \pm 1.26 \mathrm{~cm}, \mathrm{P}$ $=0.56$ ). No congenital anomaly was observed in the two groups.

\section{Discussion}

None of the medications studied in the current trial, including ondansetron and vitamin B6, showed any significant difference in neonatal outcomes including neonatal anomaly and anthropometric parameters changes. Also, the two drugs had no side effects as congenital abnormalities. In fact, the prescription of both antiemetic drugs was safe in terms of neonatal early outcomes. Furthermore, ondansetron and vitamin B6 were both effective in relieving pregnancy-related nausea and vomiting and led to favorite pregnancy outcomes. The investigations by Pasternak and Ghahiri showed that ondansetron was superior to treat morning sickness but Koren G. was concerned about ondansetron's unproven maternal and fetal safety (7, 9, 12). However, the studies mostly focused on the efficacy of the two drugs on relieving morning sickness, not the outcomes of pregnancy. However to the best of the authors" knowledge, no study was previously published on neonatal outcomes following the use of ondansetron compared to that of vitamin B6. In a study by Oliveira et al. (13) and in contrary to the current study observations, patients in the ondansetron group were more likely to have an improvement in their nausea compared with the ones in the vitamin B6 group, in the five-day treatment course. Females using ondansetron reported less vomiting, although the neonatal outcomes were not compared between the two groups. In this context, the neonatal consequences of two groups were assessed separately. While fetal safety data for vitamin B6 or its combination with doxylamine are based on more than a quarter of a million pregnancies, the fetal safety data for ondansetron are based on fewer than 200 births (14). A recent case-control study suggested an increased risk of cleft palate associated with ondansetron. Recently, the FDA issued a warning about potentially serious QT prolongation and torsade de pointes associated with ondansetron use (7). Importantly, a recent large control study by the Slone epidemiology center in Boston, MA, and the centers for disease control and prevention in Atlanta, GA, detected a 2-fold increased risk of cleft palate associated with ondansetron taken for nausea and vomiting of pregnancy (NVP) in the first trimester of pregnancy (15). On the other hand, the safety of ondansetron was addressed by the mother risk program in 2004 through a prospective cohort study of 176 females, in whom they could not detect an increased teratogenic risk. However, this sample size ruled out only a five-fold increased risk of major malformations and not any specific malformation. Moreover, the lack of other similar cohort studies precluded conducting a meta-analysis to increase the sample size (16). Besides, no previous reports were available on toxicity or teratogenicity of vitamin B6 during pregnancy. However, it seems that the high-dosage use may be accompanied by maternal toxicity. Its optimal efficacy and safety is indicated with the standard therapeutic doses up to 500 $\mathrm{mg} /$ day without increasing maternal adverse effect or jeopardizing fetal safety, but concerns about maternal toxicity are reported with dosages much higher than $500 \mathrm{mg} /$ day, and in the $2000-6000 \mathrm{mg} /$ day range (17). Hence, although the use of doxylamine/vitamin B6 combination is recommended to relive morning sickness in pregnant females based on the large body of evidence that exists for their efficacy and safety; however, the lack of neonatal abnormalities especially on neonatal anthropometric indices following the use of both drugs, none of the drugs is superior regarding neonatal safety.

In conclusion, with respect to the neonatal safety of vitamin B6 and ondansetron, both drugs can be applied to relive morning sickness to ensure the absence of neonatal adverse outcomes. However, due to some cardiac-related adverse consequences of ondansetron or the probability of maternal toxicity in the use of high-dose vitamin B6, it is recommended to use both drugs cautiously.

\subsection{Limitation}

We have to declare that however the pills were in paper box packages but it cannot cause impossible detection of drug type and standard shape and color of each drug make the study at the risk of loss in blinding, specifically at observer level. 


\section{Footnote}

Authors' Contribution: Developing the original idea data gathering, manuscript writing, technical and material support, and the study observer, Zahra Shahraki; data gathering, Forough Forghani; data abstraction and analysis contributing, Zohre Hashemi; preparing the manuscript, Rezvane Nakhai.

\section{References}

1. Ferreira E, Gillet M, Lelievre J, Bussieres JF. Ondansetron use during pregnancy: a case series. J Popul Ther Clin Pharmacol. 2012;19(1):1-10. [PubMed: 22267256].

2. Davis M. Nausea and vomiting of pregnancy: an evidence-based review. J Perinat Neonatal Nurs. 2004;18(4):312-28. [PubMed: 15646303].

3. Alexander R, Lovell AT, Seingry D, Jones RM. Comparison of ondansetron and droperidol in reducing postoperative nausea and vomiting associated with patient-controlled analgesia. Anaesthesia. 1995;50(12):1086-8. [PubMed: 8546294].

4. Cunningham FG, Leveno KJ, Hauth JC, Rouse DJ, Spong CY. Williams Obstetrics. United States of America: McGraw-Hill Medical; 2010.

5. Eisenberg DM, Davis RB, Ettner SL, Appel S, Wilkey S, Van Rompay M, et al. Trends in alternative medicine use in the United States, 19901997: results of a follow-up national survey. JAMA. 1998;280(18):156975. [PubMed: 9820257].

6. Gridelli C, Haiderali AM, Russo MW, Blackburn LM, Lykopoulos K. Casopitant improves the quality of life in patients receiving highly emetogenic chemotherapy. Support Care Cancer. 2010;18(11):1437-44. doi: 10.1007/s00520-009-0766-4. [PubMed: 19882176].

7. Koren G. Motherisk update. Is ondansetron safe for use during pregnancy?. Can Fam Physician. 2012;58(10):1092-3. [PubMed: 23064917].

8. Pasternak B, Svanstrom H, Hviid A. Ondansetron in pregnancy and risk of adverse fetal outcomes. $N$ Engl J Med. 2013;368(9):814-23. doi: 10.1056/NEJMoa1211035. [PubMed: 23445092].
9. Koren G. Treating morning sickness in the United States-changes in prescribing are needed. Am J Obstet Gynecol. 2014;211(6):602-6. doi: 10.1016/j.ajog.2014.08.017. [PubMed: 25151184].

10. King TL, Murphy PA. Evidence-based approaches to managing nausea and vomiting in early pregnancy. J Midwifery Womens Health. 2009;54(6):430-44. doi: 10.1016/j.jmwh.2009.08.005. [PubMed: 19879515].

11. Sahakian V, Rouse D, Sipes S, Rose N, Niebyl J. Vitamin B6 is effective therapy for nausea and vomiting of pregnancy: a randomized, double-blind placebo-controlled study. Obstet Gynecol. 1991;78(1):336. [PubMed: 2047064].

12. Ghahiri AA, Abdi F, Mastoo R, Ghasemi M. The Effect of Ondansetron and Metoclopramide in Nausea and Vomiting of Pregnancy. I Isfahan MedSchool. 2011;29(131)

13. Oliveira LG, Capp SM, You WB, Riffenburgh RH, Carstairs SD. Ondansetron compared with doxylamine and pyridoxine for treatment of nausea in pregnancy: a randomized controlled trial. Obstet Gynecol. 2014;124(4):735-42. doi:10.1097|AOG.0000000000000479. [PubMed: 25198265].

14. NA. Ondansetron looks safe in pregnancy, so far. BMJ. 2013;346:1387 doi: 10.1136/bmj.f1387. [PubMed: 23468289].

15. Einarson A, Maltepe C, Navioz Y, Kennedy D, Tan MP, Koren G The safety of ondansetron for nausea and vomiting of pregnancy: a prospective comparative study. BJOG. 2004;111(9):940-3. doi: 10.1111/j.1471-0528.2004.00236.x. [PubMed: 15327608].

16. Anderka M, Mitchell AA, Louik C, Werler MM, Hernandez-Diaz S, Rasmussen SA, et al. Medications used to treat nausea and vomiting of pregnancy and the risk of selected birth defects. Birth Defects Res A Clin Mol Teratol. 2012;94(1):22-30. doi: 10.1002/bdra.22865. [PubMed: 22102545].

17. Shrim A, Boskovic R, Maltepe C, Navios Y, Garcia-Bournissen F, Koren G. Pregnancy outcome following use of large doses of vitamin B6 in the first trimester. J Obstet Gynaecol. 2006;26(8):749-51. doi: 10.1080/01443610600955826. [PubMed: 17130022]. 